\title{
Microstructural characterization of Eurofer-97 and Eurofer-ODS steels before and after multi-beam ion irradiations at JANNUS Saclay facility
}

\author{
Daniel Brimbal ${ }^{a}$, , Lucile Beck ${ }^{a}$, Oliver Troeber ${ }^{b}$, Ermile Gaganidze ${ }^{b}$, Patrick Trocellier ${ }^{\mathrm{a}}$, \\ Jarir Aktaa ${ }^{\mathrm{b}}$, Rainer Lindau ${ }^{\mathrm{b}}$ \\ ${ }^{a}$ CEA, DEN, Service de Recherches de Métallurgie Physique, Laboratoire JANNUS, F-91191, Gif-sur-Yvette, France \\ ${ }^{\mathrm{b}}$ Karlsruhe Institute of Technology, Institute for Applied Materials, P.O. Box 3640, 76021, Karlsruhe, Germany
}

\begin{abstract}
RAFM steels such as Eurofer-97 and Eurofer-ODS are potential structural materials for future fusion reactors. In order to study their resistance to the high energy neutrons they will be subjected to in this context, we have irradiated these materials in single-, dual- and triple-beam mode to $26 \mathrm{dpa}$ at $400{ }^{\circ} \mathrm{C}$. In single-beam mode (Fe ions only), both materials resist swelling but dislocation loops form. For dual- (Fe and $\mathrm{He}$ ions) and triple-beam ( $\mathrm{Fe}, \mathrm{He}$ and $\mathrm{H}$ ) modes, the same dislocation loop microstructure is observed as for the single-beam mode, but small cavities form, aided by the presence of gases. Despite the formation of cavities, swelling is very low for the present conditions. The influence of ODS particles on swelling is briefly discussed.
\end{abstract}

\section{Introduction}

Reduced-activation ferritic-martensitic (RAFM) steels are considered to be the most promising materials for a use as structural materials in future fusion reactors [1,2], thanks to their low activation by neutron irradiation, their low swelling under irradiation and their good thermo-mechanical properties [1]. However, some questions remain concerning their resistance to swelling in the presence of helium and hydrogen produced by transmutation reactions due to $14 \mathrm{MeV}$ neutron irradiation [3]. High temperature

\footnotetext{
* Corresponding author. AREVA NP, Tour AREVA, 1, pl. Jean Millier, 92084, Paris La Défense, France.

E-mail addresses: Daniel.brimbal@areva.com (D. Brimbal), Lucile.beck@cea.fr (L. Beck), Oliver.troeber@kit.edu (O. Troeber), Ermile.gaganidze@kit.edu (E. Gaganidze), Patrick.trocellier@cea.fr (P. Trocellier), Jarir.aktaa@kit.edu (J. Aktaa), Rainer.lindau@kit.edu (R. Lindau).
}

helium embrittlement could also potentially be a problem [4-7]. Before a facility like IFMIF [8] that will produce high fluxes of $14 \mathrm{MeV}$ neutrons is available, one of the best ways to study the combined effects of irradiation and simultaneous gas production is a multibeam ion-irradiation facility like JANNUS Saclay [9,10]. In this paper we present results concerning the microstructure of EUROFER97 and EUROFER-ODS $\left(0.5 \mathrm{wt} . \% \mathrm{Y}_{2} \mathrm{O}_{3}\right)$ steels after ion-irradiation.

The response of these materials to irradiation has been studied several times, however, to our knowledge, charged-particle multibeam irradiations of these materials have not yet been reported. Hereafter, we present a short review of previous results concerning the irradiation of EUROFER-97 and EUROFER-ODS, with emphasis on microstructural characterizations.

EUROFER-97 has been studied extensively following neutron irradiations in HFR Petten and BOR-60. Klimenkov et al. [11] irradiated EUROFER-97 to $16.3 \mathrm{dpa}$ in HFR at temperatures from $250{ }^{\circ} \mathrm{C}$ to $450{ }^{\circ} \mathrm{C}$. They showed that the dislocation loop density peaks at 
$4 \times 10^{21} \mathrm{~m}^{-3}$ for a temperature of $300{ }^{\circ} \mathrm{C}$ and that the average loop diameter goes from $7 \mathrm{~nm}$ at $250{ }^{\circ} \mathrm{C}$ to $35 \mathrm{~nm}$ at $350{ }^{\circ} \mathrm{C}$ then back down to $10 \mathrm{~nm}$ at $450^{\circ} \mathrm{C}$. For all temperatures, the authors report that all dislocations loops had $\mathrm{a}_{0} / 2<111>$ type Burgers vectors. At 350 and $400{ }^{\circ} \mathrm{C}$, a small density of cavities was detected. Due to the very low boron content of EUROFER-97, the total helium concentration is estimated as $<10$ appm for these irradiations.

EUROFER-97 was also irradiated in BOR-60 to 15 and $32 \mathrm{dpa}$, but for only one temperature: $330{ }^{\circ} \mathrm{C}$ (final He content well below $10 \mathrm{appm}$ ) [12]. Interstitial clusters/dislocation loops are reported to be present at $15 \mathrm{dpa}$ with a mean size of $3.4 \mathrm{~nm}$ and a density of $1.4 \times 10^{22} \mathrm{~m}^{-3}$ and at $32 \mathrm{dpa}$ with a mean size of $4.8 \mathrm{~nm}$ and a density of $1.7 \times 10^{22} \mathrm{~m}^{-3}$. Small cavities are detected for both conditions. At $15 \mathrm{dpa}$, their mean size is $2.6 \mathrm{~nm}$ and their density is $3.6 \times 10^{20} \mathrm{~m}^{-3}$. At $32 \mathrm{dpa}$, their mean size is $1.6 \mathrm{~nm}$ and their density is $2.3 \times 10^{21} \mathrm{~m}^{-3}$.

The higher loop density obtained by Weiss et al. [12] at $15 \mathrm{dpa}$ in BOR-60 compared to Klimenkov et al. [11] at similar temperatures can be explained by the fact that the later authors only counted defects clearly resolvable as dislocation loops.

Boron-doping has also been used to study the combined effects of neutron irradiation and helium production. In HFR [6,13], concentrations of $\sim 80 \mathrm{appm} \mathrm{He}, \sim 415 \mathrm{appm}$ He and $\sim 5800 \mathrm{appm} \mathrm{He}$ were obtained for EUROFER-97 melted with various amounts of boron and irradiated to $16.3 \mathrm{dpa}$. Irradiation temperature went from 250 to $450{ }^{\circ} \mathrm{C}$. Dislocation loops, $\alpha$-precipitates and helium bubbles were observed by TEM after irradiation. For all specimens, He bubble size increases with irradiation temperature. For helium concentrations of $82 \mathrm{appm}$ and $412 \mathrm{appm}$, it is shown that no cavities formed after irradiation at $250{ }^{\circ} \mathrm{C}$ (except at boron containing precipitates), randomly distributed cavities formed at $350{ }^{\circ} \mathrm{C}$ and preferential nucleation of smaller cavities on dislocations and grain boundaries occurred at $450{ }^{\circ} \mathrm{C}$ [6]. The swelling was maximal at a temperature of $350{ }^{\circ} \mathrm{C}$ at around $0.6 \%$. Note that the use of boron presents some artifacts: first of all, in the $83 \mathrm{ppm}{ }^{10} \mathrm{~B} /$ 415 appm He sample, all B is transmuted in to He by $1 \mathrm{dpa}$. For other irradiations, some boron is still present at $16.3 \mathrm{dpa}$, and boron inclusions as well as $(\mathrm{Cr}, \mathrm{Fe}) \mathrm{B}$ and $\mathrm{B}(\mathrm{C}, \mathrm{N})$ precipitates formed. This later feature means that the helium is produced heterogeneously to some extent. After irradiation to $250^{\circ} \mathrm{C}$, the presence of nanometer sized bubbles localized around boron containing precipitates was observed in a sample that otherwise did not contain bubbles [6]. On the other hand for an irradiation temperature of $250{ }^{\circ} \mathrm{C}$ and for a helium content of 412 appm the presence of nearly homogeneously distributed helium bubbles were found [13]. Comparison of these results with the findings in Ref. [6] indicates a non-homogeneous distribution of boron in the investigated RAFM steel. The present experiments by dual-beam ion irradiation may enable us to get more insight on the importance of such artifacts.

Small-angle neutron scattering (SANS) experiments have also been done on EUROFER-97 irradiated in HFR Petten up to doses of 2.5, 8.4, and $16.5 \mathrm{dpa}$ at temperatures 250 and $300{ }^{\circ} \mathrm{C}$ (without boron). SANS experiments show that microvoids and $\alpha^{\prime}$ precipitates are present after irradiation, the $\alpha^{\prime}$ precipitates becoming dominant at $16.5 \mathrm{dpa}$. Between 2.4 and $8.9 \mathrm{dpa}$, the volume fraction of microvoids increases by a factor of nearly 2 while the average size of microvoids remains nearly unchanged [14].

Eurofer-97 has also been irradiated within STIP-II and STIP-III [15,16]. For STIP-II, EUROFER-97 samples irradiated with protons to $20.4 \mathrm{dpa} / 1795$ appm He at a mean temperature of $309{ }^{\circ} \mathrm{C}$ contained very small cavities with sizes between 1.0 and $1.5 \mathrm{~nm}$ as well as dislocation loops (resolvable loops + black dots) with a density of $4.3 \times 10^{22} \mathrm{~m}^{-3}$ and average diameter of $6.1 \mathrm{~nm}$. At $20.4 \mathrm{dpa} /$ $1795 \mathrm{appm} \mathrm{He}$ and $357^{\circ} \mathrm{C}$, the average cavity diameter was $2.5 \mathrm{~nm}$ and the density was $4.4 \times 10^{23} \mathrm{~m}^{-3}$. The dislocation loop density was $3.1 \times 10^{22} \mathrm{~m}^{-3}$ with an average diameter of $7.2 \mathrm{~nm}$. Note however that the temperature varies greatly during such experiments, for example the specimen irradiated at a mean temperature of $357^{\circ} \mathrm{C}$ suffered excursions to 309 and $406{ }^{\circ} \mathrm{C}$ [16]. Furthermore, for these spallation target irradiations, specimens are irradiated with protons and neutrons simultaneously. This makes the interpretation of results difficult.

Eurofer-ODS has also been studied after irradiation, usually by tomographic atom probe (TAP), in order to obtain data on nanoparticles enriched in yttrium and oxygen [17,18]. In Eurofer-ODS $\left(0.3 \mathrm{wt} . \% \mathrm{Y}_{2} \mathrm{O}_{3}\right)$ Williams et al. [17] did not detect any variation of particle size distribution and in the particle composition after Fe ion irradiations to $2 \mathrm{dpa}$ at $400^{\circ} \mathrm{C}$. However, Rogozhkin et al. [18,19] found an increase of the particle density after irradiation and a loss of vanadium in particles in Eurofer-ODS $\left(0.5 \mathrm{wt} . \% \mathrm{Y}_{2} \mathrm{O}_{3}\right)$ irradiated to $32 \mathrm{dpa}$ at $330^{\circ} \mathrm{C}$. The same team irradiated TAP needles of EuroferODS with Fe ions at room temperature to three doses: 3.2,10.2 and 13.2 dpa [19]. Pre-existing particles of Y, O, N and V were still visible with the same size and density after irradiation, but there was practically no more $\mathrm{N}$ and $\mathrm{V}$ in them. TEM characterization of irradiated Eurofer-ODS containing 0.5wt.\% $\mathrm{Y}_{2} \mathrm{O}_{3}$ is missing for the moment.

\section{Experimental procedure}

EUROFER 97 samples are from heat E83697 produced by Böhler Austria GmbH. Final heat treatment is a normalisation at $980{ }^{\circ} \mathrm{C}$ for $30 \mathrm{~min}$ plus tempering at $760{ }^{\circ} \mathrm{C}$ for $90 \mathrm{~min}$ followed by air cooling. EUROFER-ODS samples are from heat HXN 958/1, produced at Plansee by mechanical alloying of EUROFER powder with $0.5 \%$ yttria. After consolidation by hot isostatic pressing, the bar was normalized at $1100{ }^{\circ} \mathrm{C}$ for 30 min followed by an air/ water quench and then tempered at $750{ }^{\circ} \mathrm{C}$ for $2 \mathrm{~h}$. Final compositions are indicated in Table 1 . For both materials, $1 \mathrm{~mm}$ thick slices were cut out and then polished mechanically to $\sim 90 \mu \mathrm{m}$, and $3 \mathrm{~mm}$ discs were finally punched out from the slices. Before irradiation, the discs were electro-polished for a few seconds in a Struers Tenupol 5 device with a 10\% perchloric acid-20\% 2butoxyethanol-70\% ethanol electrolyte, at room temperature and a voltage of $49 \mathrm{~V}$ in order to remove damage due to mechanical polishing.

The irradiations were performed in the triple-beam ion facility at JANNUS Saclay [9] in single- $\left(3 \mathrm{MeV} \mathrm{Fe}^{3+}\right)$, dual- $\left(3 \mathrm{MeV} \mathrm{Fe}^{3+}\right.$ and 1.2 $\mathrm{MeV} \mathrm{He}^{+}$) and triple-beam (3 $\mathrm{MeV} \mathrm{Fe}^{3+}, 1.2 \mathrm{MeV} \mathrm{He}^{+}$and $600 \mathrm{keV} \mathrm{H}^{+}$) modes. All three irradiations were done at $400 \pm 10^{\circ} \mathrm{C}$. The sample temperature during irradiation was controlled by thermocouples and an FLIR infrared camera. $\mathrm{He}^{+}$and $\mathrm{H}^{+}$ions were

Table 1

Compositions of as-received Eurofer-97 [20] and Eurofer-ODS (0.5wt.\% $\left.\mathrm{Y}_{2} \mathrm{O}_{3}\right)$ in wt.\%.

\begin{tabular}{lll}
\hline Material & Eurofer-97 & Eurofer-ODS \\
\hline Cr & 8.91 & 9.40 \\
$\mathrm{C}$ & 0.12 & 0.072 \\
$\mathrm{Mn}$ & 0.48 & 0.418 \\
$\mathrm{P}$ & 0.005 & $<0.04$ \\
$\mathrm{~S}$ & 0.004 & 0.0036 \\
$\mathrm{~V}$ & 0.2 & 0.185 \\
$\mathrm{~B}$ & 0.001 & $<0.005$ \\
$\mathrm{~N}$ & 0.02 & 0.029 \\
$\mathrm{O}$ & 0.0008 & 0.171 \\
$\mathrm{Y}$ & Not specified & 0.297 \\
$\mathrm{~W}$ & 1.08 & 1.10 \\
$\mathrm{Ta}$ & 0.14 & 0.08 \\
$\mathrm{Ti}$ & 0.006 & 0.001 \\
$\mathrm{Fe}$ & Balance & Balance \\
\hline
\end{tabular}




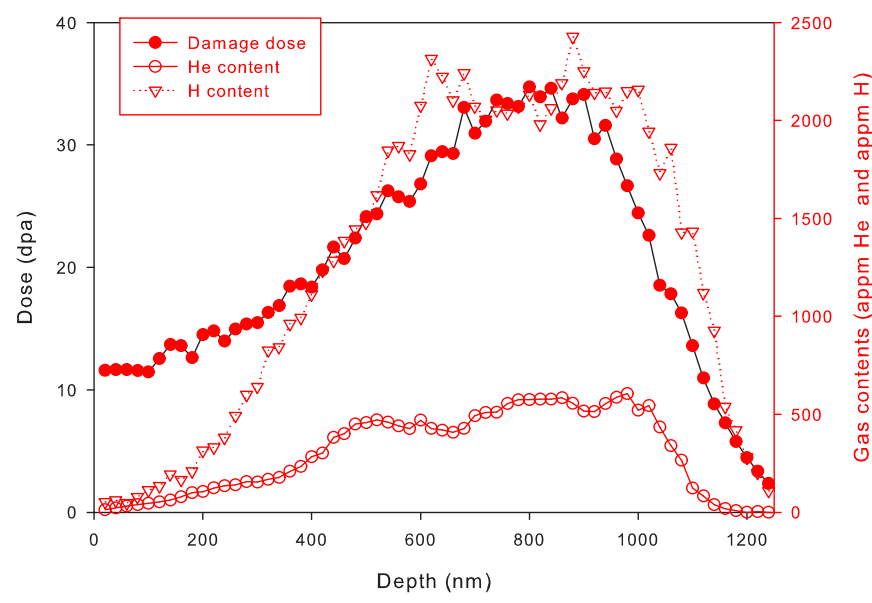

Fig. 1. Damage and implanted gas content profiles for the triple-beam irradiation to 27 dpa/440 appm He/2000 appm He calculated by SRIM [21] calculations.

implanted using energy degraders [10] made of thin aluminium foils. Periodic beam current measurements were performed with a system made up of three groups of seven Faraday cups, in order to calculate ion fluxes and fluences. All three beams were rasterscanned.

All damage levels and gas implantation rates were calculated using SRIM-2008 [21] ( $E_{\mathrm{d}}=40 \mathrm{eV}$ and Kinchin and Pease calculation, for a good comparison with neutron irradiation experiments [22]). The damage and gas implantation profiles for the triple-beam irradiation are presented in Fig. 1. Gas implantation profiles were calculated using the method explained previously [23], taking into account the ion beam divergence induced by the energy degraders. We have limited our study to the zone situated between 500 and $700 \mathrm{~nm}$, in order to avoid surface effects and the injected interstitial effect $[24,25]$. Mean damage doses and gas contents for this socalled "analysed zone" between 500 and $700 \mathrm{~nm}$ are given in Table 2. Helium and hydrogen to dpa ratios were 17 appmHe/dpa for the dual-beam irradiation and 16 appm He/dpa and $74 \mathrm{appm} \mathrm{H/}$ dpa for the triple-beam irradiation, in order to approach conditions predicted for structural materials in fusion reactors $[3,26]$.

After irradiation, transmission electron microscopy (TEM) specimens were prepared by electro-polishing in three steps using a Tenupol 5:

1. Front-side electro-polish to remove $500 \mathrm{~nm}$ using a $5 \%$ perchloric acid-95\% ethanol electrolyte at $-40{ }^{\circ} \mathrm{C}$ and $40 \mathrm{~V}$.

2. Application of a lacomit layer on the front-side (irradiated side) of the specimen.

3. Back-side electro-polish to pierce a hole with the aforementioned 10\% perchloric acid-20\% 2-butoxyethanol-70\% ethanol electrolyte, at room temperature and $49 \mathrm{~V}$.

Also, transverse specimens were prepared with a focused ion beam (FEI Helios NanoLab 650) and allowed confirmation of the results obtained from the electro-polished specimens.

Table 2

Conditions for irradiations performed at $400{ }^{\circ} \mathrm{C}$ in single-, dual- and triple-beam modes. Averages calculated over depths from 500 to $700 \mathrm{~nm}$ depth.

\begin{tabular}{llll}
\hline Irradiation mode & Dose & Damage rate & Final gas content \\
\hline Single-beam & $26 \mathrm{dpa}$ & $1.4 \times 10^{-3} \mathrm{dpa} / \mathrm{s}$ & 0 \\
Dual-beam & $26 \mathrm{dpa}$ & $1.1 \times 10^{-3} \mathrm{dpa} / \mathrm{s}$ & $430 \mathrm{appm} \mathrm{He}$ \\
Triple-beam & $27 \mathrm{dpa}$ & $1.3 \times 10^{-3} \mathrm{dpa} / \mathrm{s}$ & $440 \mathrm{appm} \mathrm{He}, 2000 \mathrm{appm} \mathrm{H}$ \\
\hline
\end{tabular}

The dislocation microstructure, nano-particles and cavities were analyzed using conventional TEM bright field conditions.

Micrographs for dislocation loop density and size analysis were done using $\overrightarrow{\mathbf{g}}=<110>$ type diffraction vectors, and it was verified that using different zone axes did not modify results significantly. Mean loop diameter values were determined by measuring over a hundred loops for each irradiation condition. For one sample, the mean loop diameter was also determined using the weak-beam dark-field method, and the value found was $1.4 \mathrm{~nm}$ lower. The mean loop diameters reported in this study were measured using the conventional bright-field method, leading to a systematic overestimation compared with measurements done with the weakbeam dark-field method. Dislocation loop Burgers vectors were determined using a simplified $\overrightarrow{\mathbf{g}} \cdot \overrightarrow{\mathbf{b}}$ analysis based on the method used by Yao et al. [27,28]. Indeed, unlike samples irradiated as thin foils, where some dislocation loops with Burgers vectors normal to the free surfaces escape to them [29], we can assume that the Burgers vectors are equiprobable amongst a given family (i.e. $a_{0} / 2$ $<111>$ family or $\mathrm{a}_{0}<100>$ family). The respective proportions of $\mathrm{a}_{0} / 2<111>$ and $\mathrm{a}_{0}<100>$ type Burgers vectors in a micrograph taken using a diffraction vector $\overrightarrow{\mathbf{g}}=[110]$ can be determined by comparison with a micrograph taken using $\overrightarrow{\mathbf{g}}=[\overline{1} 10]$, as demonstrated in Fig. 2. Indeed, loops with $\overrightarrow{\mathbf{b}}= \pm \mathrm{a}_{0}[100]$ and $\overrightarrow{\mathbf{b}}= \pm \mathrm{a}_{0}$ $[010]$ are visible in both micrographs whereas loops with $\overrightarrow{\mathbf{b}}= \pm \mathrm{a}_{0} / 2$ [111] and $\overrightarrow{\mathbf{b}}= \pm \mathrm{a}_{0} / 2$ [11-1] are visible in the first micrograph but not in the second. Using the assumption that Burgers vectors are equiprobable amongst a given family, one can then calculate the total proportions of $a_{0} / 2<111>$ and $a_{0}<100>$ families from the proportions observed in the first micrograph with $\overrightarrow{\mathbf{g}}=[110]$. The proportion of observed $a_{0}<100>$ Burgers vectors is multiplied by $3 /$ 2 and the proportion of observed $\mathrm{a}_{0} / 2<111>$ type Burgers vectors is multiplied by 2 . In a similar manner, total dislocation loop densities are calculated from the visible loops in a $\overrightarrow{\mathbf{g}}=<110>$ micrograph.

Cavities were analyzed by doing through focal series. Due to the very small sizes of observed cavities, large errors are expected for diameter measurements and density measurements [30].

Thickness measurements were done by counting the thickness fringes in a two-beam bright-field condition or by the contamination spot separation method [31]. The thickness measurement is the major source of errors for dislocation density determinations, and causes an uncertainty of $\pm 10 \%$.

\section{Experimental results}

\subsection{Eurofer-97 and Eurofer-ODS before irradiation}

Although excellent studies of non-irradiated Eurofer-97 [2,20] and Eurofer-ODS [32] have already been presented, some details are given here for clarity.

Eurofer-97 has a tempered martensite structure, as can be seen in Fig. 3(a). The dislocation density in the laths is $9.0 \times 10^{13} \mathrm{~m}^{-2}$. Precipitates decorate the lath boundaries, but are seldom found inside laths.

Eurofer-ODS has a duplex microstructure: some grains are ferritic (Fig. 3(b)), whereas others contain tempered martensite (Fig. 3(c)). The dislocation and nano-particle microstructures in the two types of grains are different. In the ferrite grains, the dislocation density is $1.8 \times 10^{13} \mathrm{~m}^{-2}$, and a high density $\left(1.6 \times 10^{22} \mathrm{~m}^{-3}\right)$ of relatively small nano-particles is present (Fig. 4(a)). In the tempered martensite grains (Fig. 4(b)), the dislocation density is $1.3 \times 10^{14} \mathrm{~m}^{-2}$, and the particles are bigger and their density is lower, at $5.2 \times 10^{21} \mathrm{~m}^{-3}$. Particle distributions for the two types of grains are given in Fig. 5: the distribution in the tempered martensite grains is wider and reaches larger sizes. Mean particle diameters are $4.6 \mathrm{~nm}$ in ferrite grains and $10.6 \mathrm{~nm}$ in tempered martensite grains. 

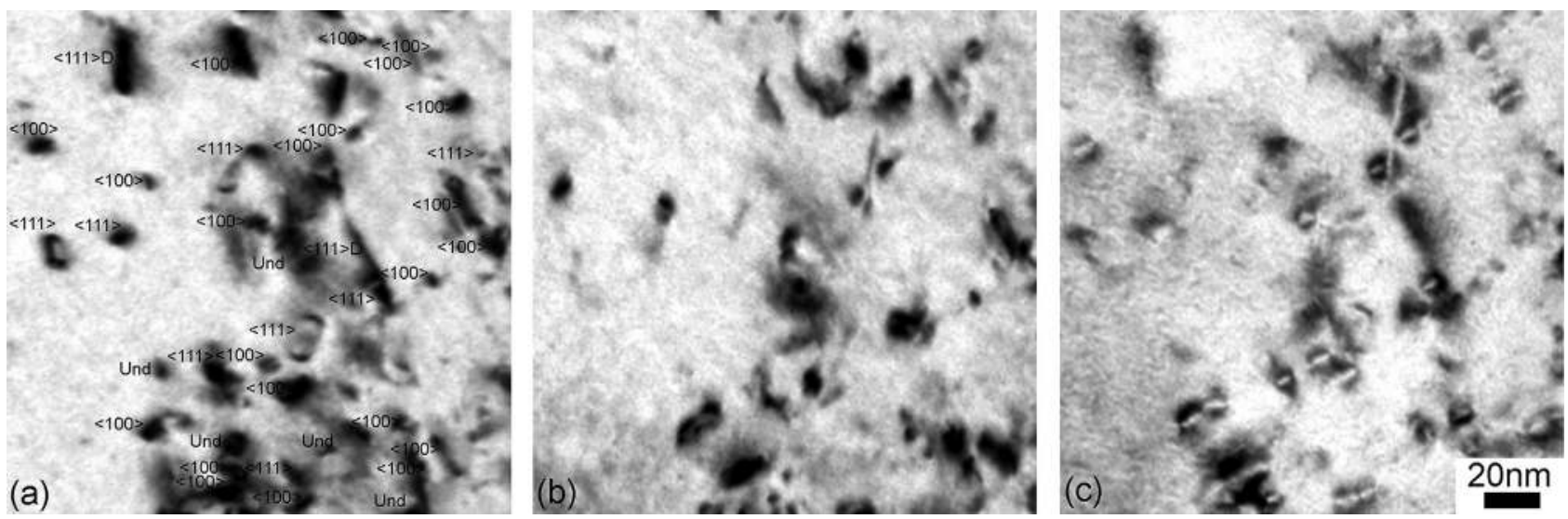

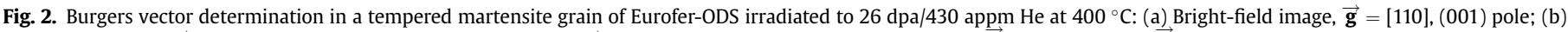

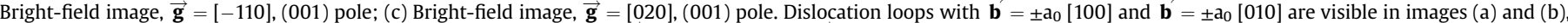

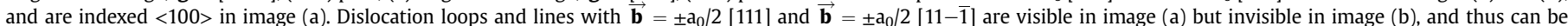

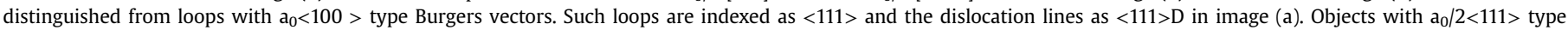

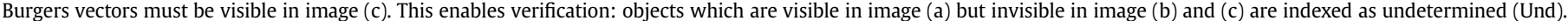
Indexes are always to the left of the corresponding object.
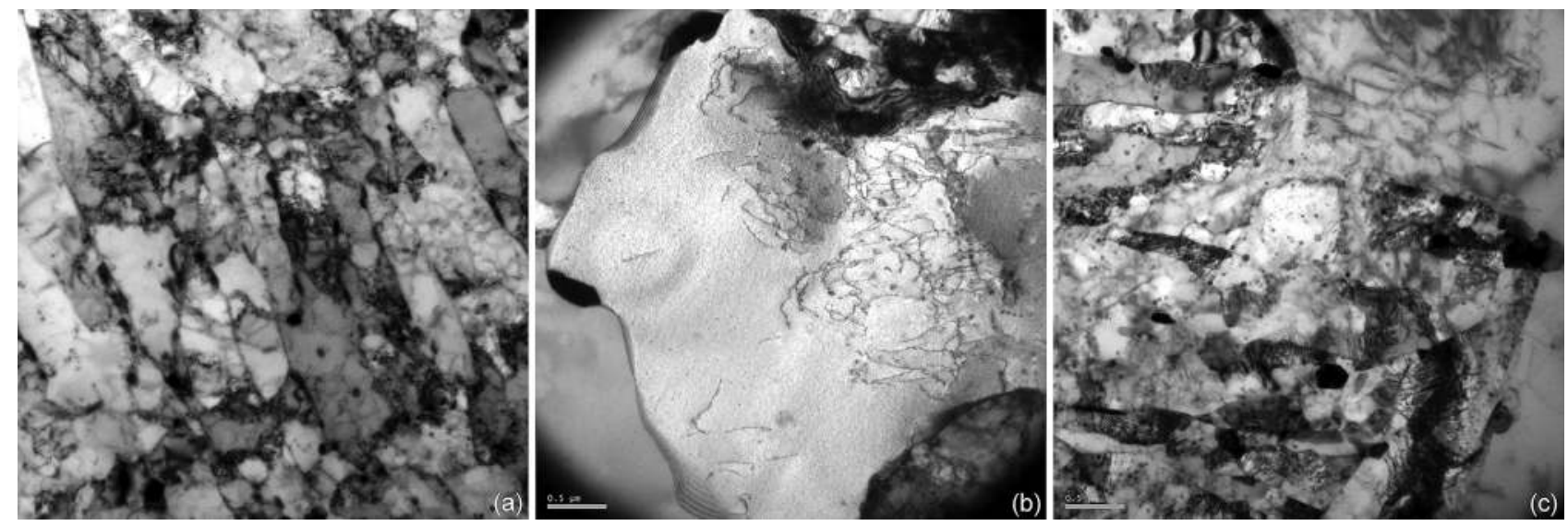

Fig. 3. Microstructures prior to irradiation in both materials. (a) Eurofer-97; (b) ferrite grain in Eurofer-ODS; (c) tempered martensite grain in Eurofer-ODS.

\subsection{Single-beam irradiation of Eurofer-97 and Eurofer-ODS}

After irradiation to $26 \mathrm{dpa}$ at $400{ }^{\circ} \mathrm{C}$, dislocation loops form in both materials (Figs. 6-8). Quantitative data for the dislocation

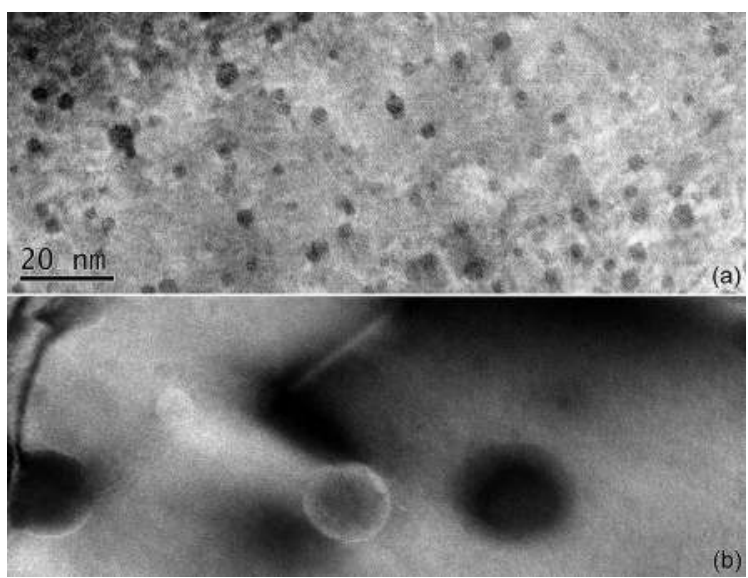

Fig. 4. Precipitate microstructure in Eurofer-ODS. (a) Small precipitates in a ferrite grain; (b) Larger precipitates in a tempered martensite grain. microstructure formed is indicated in Table 3. In Eurofer-97, the majority of dislocation loops have an $\mathrm{a}_{0}<100>$ type Burgers vector (see Table 4 for Burgers vector analysis) and are situated in $\{100\}$ type planes (see Fig. 9). A small proportion of the dislocation loops

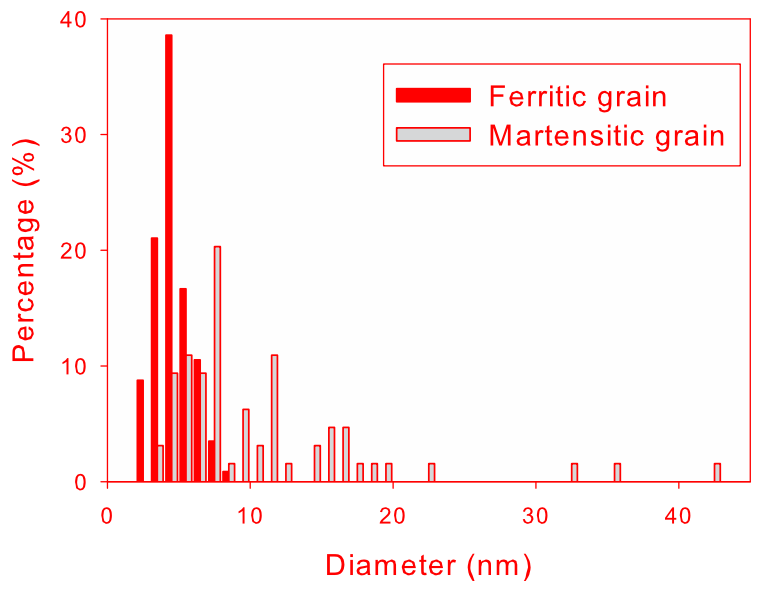

Fig. 5. Precipitate distributions in both grain types in Eurofer-ODS. 


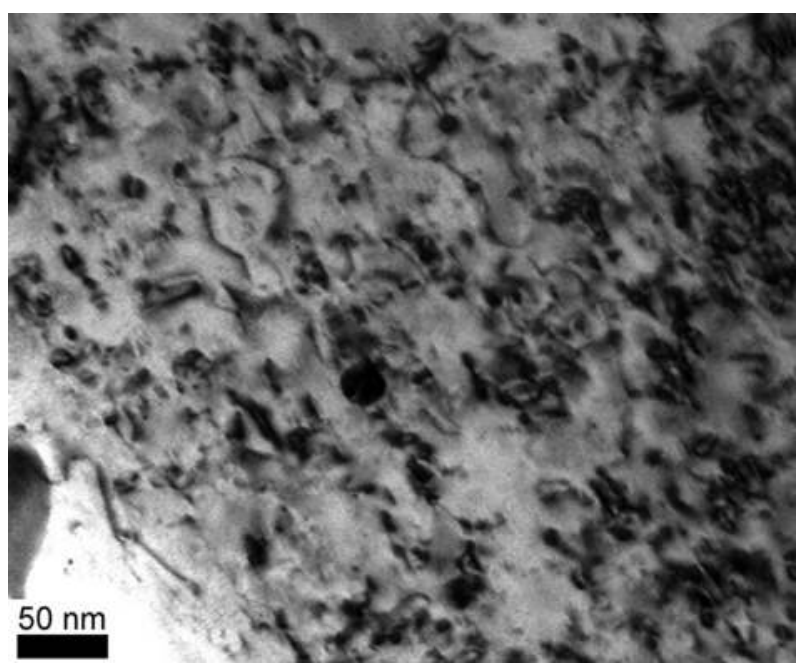

Fig. 6. Dislocation microstructure in Eurofer- 97 irradiated to $26 \mathrm{dpa}$ at $400{ }^{\circ} \mathrm{C}$ with $3 \mathrm{MeV} \mathrm{Fe}{ }^{3+}$ ions (bright-field image, $\overrightarrow{\mathbf{g}}=<110>$ ).

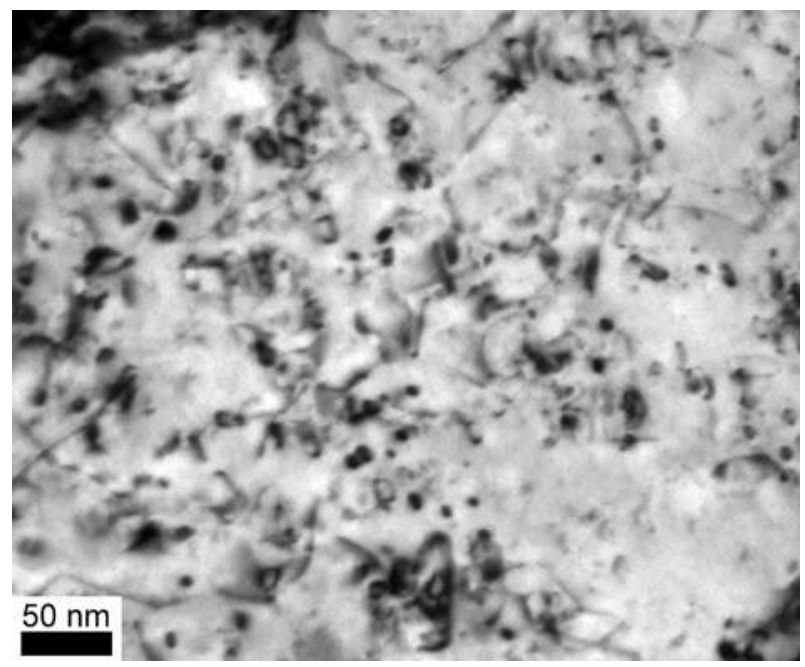

Fig. 7. Dislocation microstructure in a tempered martensite grain of Eurofer-ODS irradiated to $26 \mathrm{dpa}$ at $400{ }^{\circ} \mathrm{C}$ with $3 \mathrm{MeV} \mathrm{Fe}^{3+}$ ions (bright-field image, $\overrightarrow{\mathbf{g}}=<110>$ ).

have $\mathrm{a}_{0} / 2<111>$ Burgers vectors. Note that all the analyzed dislocation lines have an $a_{0} / 2<111>$ Burgers vector.

The dislocation microstructure of the tempered martensite grains of Eurofer-ODS (Fig. 7) is similar to the one observed in Eurofer-97. Dislocation loop densities and sizes are similar, as seen in Table 3. Also, the proportion of loops with $\mathrm{a}_{0}<100>$ type Burgers is high in both materials, over $75 \%$.

However, the dislocation microstructure in Eurofer-ODS ferrite grains is quite different (Fig. 8). There are less dislocation loops, but the dislocation network is more developed, so that the dislocation density, which takes into account both dislocation loops and dislocation lines, is quite similar for all types of grains and materials (Table 3). The Burgers vector analysis for ferrite grains shows that most dislocation loops have a $\mathrm{a}_{0} / 2<111>$ Burgers vector, contrary to the Eurofer- 97 and tempered martensite grains of Eurofer-ODS.

For the single-beam irradiation, no cavities are detected in either material. We also note that in both grain types of EuroferODS, no evolution of the oxide particle microstructure is detected.

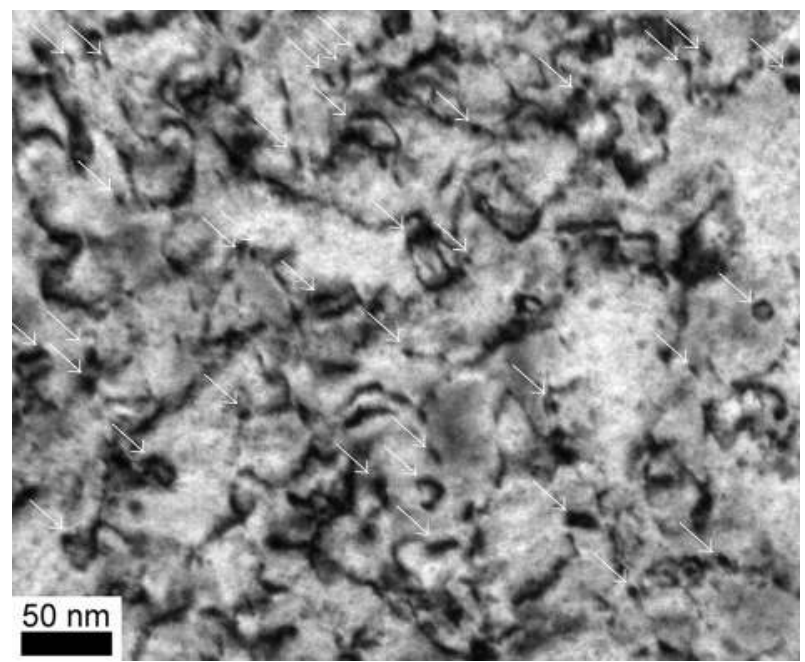

Fig. 8. Dislocation microstructure in a ferrite grain of Eurofer- 97 irradiated to $26 \mathrm{dpa}$ at $400{ }^{\circ} \mathrm{C}$ with $3 \mathrm{MeV} \mathrm{Fe}^{3+}$ ions (bright-field image, $\overrightarrow{\mathbf{g}}=<110>$ ). White arrows indicate objects counted as dislocation loops.

\subsection{Multi-beam irradiations of Eurofer-97 and Eurofer-ODS: effects of gas ion implantation}

Gas ion implantation has no detectable effect on the densities, size distributions and Burgers vectors of loops, which are similar to the ones determined for the single-beam irradiation in both materials.

However, gas ion implantation has an effect on the cavity microstructure. For both multi-beam irradiations, small cavities are detected in Eurofer-97 and in the tempered martensite grains of Eurofer-ODS. No cavities are detected in the ferrite grains. Measured cavity densities and mean diameters are indicated in Table 5. The cavity microstructure is presented in Figs. 10 and 11 for the dual-beam irradiation and in Figs. 12 and 13 for the triple-beam irradiation. Swelling values calculated from TEM data stay inferior to $0.1 \%$ for Eurofer-97 and Eurofer-ODS for both multi-beam irradiations.

Due to the low cavity density and the high irradiation dose, we could not discern whether the cavity formation was heterogeneous or not.

\section{Discussion}

\subsection{Single-beam irradiation of Eurofer-97 and Eurofer-ODS}

Our results concerning Eurofer-97 may be compared to those obtained after neutron irradiations in HFR and BOR-60 [11,12]. Our counting method resembled the one used by Weiss et al. [12], so our results are most easily compared with theirs. After irradiation to $32 \mathrm{dpa}$ at $330{ }^{\circ} \mathrm{C}$, they find a dislocation loop density of $1.7 \times 10^{22} \mathrm{~m}^{-3}$ and a mean loop size of $4.8 \mathrm{~nm}$. These values are close but inferior to the ones we have observed (see Table 3). This indicates that there is a temperature shift of about $70{ }^{\circ} \mathrm{C}$ between neutron and ion irradiation experiments, i.e. to simulate the effects of lower damage rates for neutron irradiations, temperatures higher by $70{ }^{\circ} \mathrm{C}$ are necessary for the higher damage rates of ion implantations. Comparison with the work of Klimenkov et al. [11] also supports the fact that the temperature shift is larger than $50{ }^{\circ} \mathrm{C}$, since they report a mean loop diameter size of $35 \mathrm{~nm}$ after irradiation to $16.3 \mathrm{dpa}$ at $350{ }^{\circ} \mathrm{C}$. Indeed, although mean loop diameters are not directly comparable, loop diameters of the largest 
Table 3

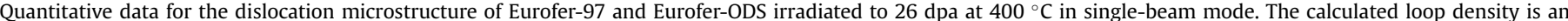

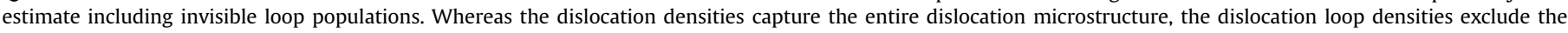
contribution from dislocation lines.

\begin{tabular}{|c|c|c|c|}
\hline Material & Eurofer-97 & Eurofer-ODS (tempered martensite grains) & Eurofer-ODS (ferrite grains) \\
\hline Counted dislocation loops & 135 & 195 & 160 \\
\hline Observed dislocation loop density $\left(10^{22} \mathrm{~m}^{-3}\right)$ & $2.3 \pm 0.2$ & $1.2 \pm 0.09$ & $0.53 \pm 0.04$ \\
\hline Calculated dislocation loop density $\left(10^{22} \mathrm{~m}^{-3}\right)$ & $3.6 \pm 0.3$ & $1.9 \pm 0.1$ & $0.96 \pm 0.08$ \\
\hline Mean loop diameter (nm) & $7.9 \pm 0.7$ & $7.1 \pm 0.5$ & $11 \pm 0.9$ \\
\hline Observed dislocation density $\left(10^{14} \mathrm{~m}^{-2}\right)$ & $6.9 \pm 0.7$ & $3.0 \pm 0.1$ & $4.0 \pm 0.4$ \\
\hline
\end{tabular}

Table 4

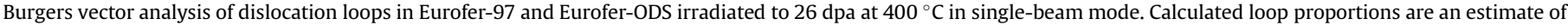
the total proportions when including invisible loops and neglecting undetermined objects.

\begin{tabular}{|c|c|c|c|}
\hline Burgers vector & Eurofer-97 & Eurofer-ODS/tempered martensite grain & Eurofer-ODS/ferrite grain \\
\hline Observed $\mathrm{a}_{0} / 2<111>$ loops & $9 \%$ & $18 \%$ & $53 \%$ \\
\hline Observed $a_{0}<100>$ loops & $80 \%$ & $76 \%$ & $33 \%$ \\
\hline Undetermined & $11 \%$ & $6 \%$ & $14 \%$ \\
\hline Number of loops analysed & 35 & 51 & 21 \\
\hline Calculated $a_{0} / 2<111>$ loops & $13 \%$ & $24 \%$ & $68 \%$ \\
\hline Calculated $\mathrm{a}_{0}<100>$ loops & $87 \%$ & $76 \%$ & $32 \%$ \\
\hline
\end{tabular}

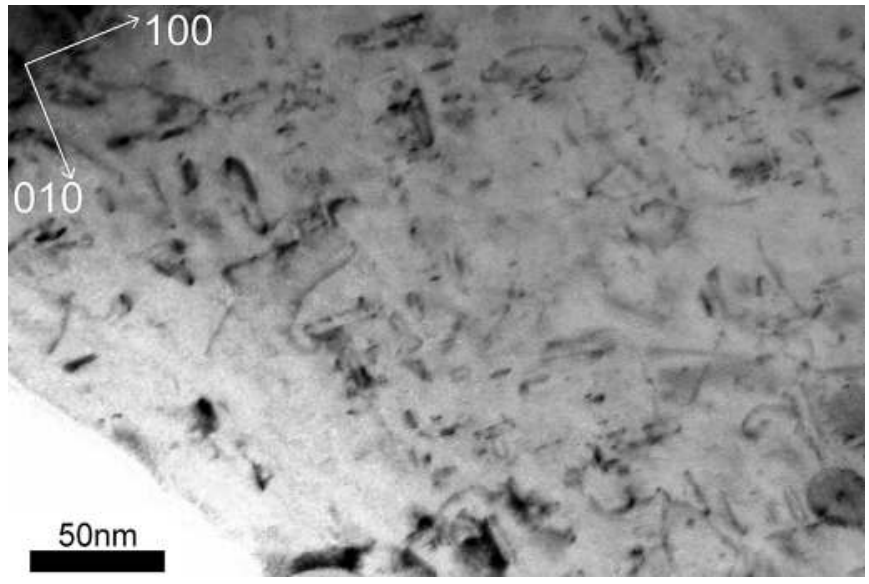

Fig. 9. Dislocation microstructure in Eurofer-97 irradiated to $26 \mathrm{dpa}$ at $400{ }^{\circ} \mathrm{C}$ with $3 \mathrm{MeV} \mathrm{Fe}^{3+}$ ions (bright-field image, $\overrightarrow{\mathbf{g}}=<110>$ ). The majority of the visible loops are edge-on and situated in $\{100\}$ type planes.

loops rarely exceed $20 \mathrm{~nm}$ in our study, so we can conclude that loops are smaller for the ion irradiation.

We show that in Eurofer-97 ion-irradiated to $26 \mathrm{dpa}$ at $400{ }^{\circ} \mathrm{C}$, $\mathrm{a}_{0}<100>$ and $\mathrm{a}_{0} / 2<111>$ type Burgers vectors coexist, and that a majority of the loops have $a_{0}<100>$ type Burgers vector. After neutron irradiation of Eurofer-97 to $32 \mathrm{dpa}$ at $330^{\circ} \mathrm{C}$, both types of Burgers vectors were found, but the majority was $a_{0} / 2<111>$ type [12]. This discrepancy could be due to different irradiation temperatures, or to the small number of loops counted. After irradiation in HFR [11], only loops with $\mathrm{a}_{0} / 2<111>$ type Burgers vectors were found in Eurofer-97 irradiated between $250{ }^{\circ} \mathrm{C}$ and $450{ }^{\circ} \mathrm{C}$. The same team has recently indicated that $\mathrm{a}_{0}<100>$ loops may also be present after neutron irradiation at $350{ }^{\circ} \mathrm{C}$ [33]. This later finding, which would be more coherent with our result, seems more plausible. Indeed, Horton et al. [34] showed that in pure iron neutron-irradiated to $1 \mathrm{dpa}$ at temperatures between 350 and $450{ }^{\circ} \mathrm{C}$, dislocation loops almost all had $\mathrm{a}_{0}<100>$ type Burgers vectors. Gelles [35] observed the microstructure of neutron irradiated $\mathrm{Fe}-9 \% \mathrm{Cr}$ and $\mathrm{Fe}-12 \% \mathrm{Cr}$ alloys. For irradiation temperatures between 400 and $450{ }^{\circ} \mathrm{C}$, both types of Burgers vectors were present in both materials. Note also that calculations of the anisotropic elastic energy of loops in pure iron showed that loops with $\mathrm{a}_{0}$ $<100>$ type Burgers vectors are the most stable at high temperatures [36].

In a 9Cr-ODS steel quite similar to Eurofer-ODS, dislocation loops formed after proton irradiation at $400{ }^{\circ} \mathrm{C}$ to about $4 \mathrm{dpa}$ [37]. Loop densities and sizes were somewhat similar to those we observe in the ferrite grains. The loop number density was slightly lower, at $3.3 \times 10^{21} \mathrm{~m}^{-3}$, and the reported average size was higher, at $15.4 \mathrm{~nm}$. These differences could be explained by the lower final damage dose and lower damage rate.

For the cavity microstructure, previous neutron-irradiations of Eurofer-97 to 15 and 32 dpa resulted in low densities of small cavities at $330{ }^{\circ} \mathrm{C}$ [12]. Our single-beam ion-irradiation experiments to similar doses do not produce any cavities. This may be due to differences in irradiation temperatures and dose rates or due to the fact that for the neutron irradiation, small quantities of helium are produced by transmutation from the few appm of boron, assisting nucleation and stabilization of cavities.

Note that the absence of cavities in a ferritic-martensitic steel ion-irradiated to low dose without helium is not surprising. Previous work on $\mathrm{Fe}-\mathrm{Cr}$ model alloys [23] has shown that no cavities appear in such materials at doses higher than those attained in this study. No cavities were formed in a $\mathrm{Fe}-9 \mathrm{Cr}-1 \mathrm{Mo}$ steel ion-

Table 5

Quantitative data on densities and sizes of cavities in Eurofer-97 and Eurofer-ODS irradiated to 26 dpa at $400{ }^{\circ} \mathrm{C}$ in dual- and triple-beam conditions.

\begin{tabular}{|c|c|c|c|c|}
\hline \multirow{2}{*}{$\frac{\text { Material }}{\text { Final gas contents }}$} & \multicolumn{2}{|l|}{ Eurofer-97 } & \multicolumn{2}{|c|}{ Eurofer-ODS (tempered martensite grains) } \\
\hline & 430 appm He & 440 appm He/2000 appm H & 430 appm He & 440 appm He/2000 appm H \\
\hline Counted cavites & 83 & 165 & 77 & 78 \\
\hline Cavity density $\left(10^{22} \mathrm{~m}^{-3}\right)$ & $1.8 \pm 0.2$ & $2.3 \pm 0.2$ & $1.4 \pm 0.2$ & $2.3 \pm 0.3$ \\
\hline Mean cavity diameter (nm) & $1.4 \pm 0.2$ & $1.9 \pm 0.1$ & $1.8 \pm 0.2$ & $2.0 \pm 0.2$ \\
\hline
\end{tabular}



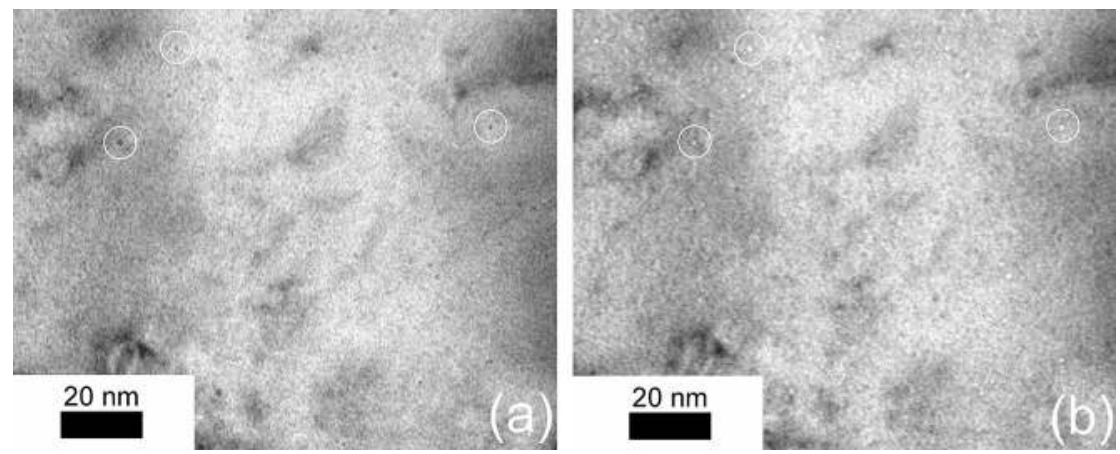

Fig. 10. Cavities in Eurofer-97 irradiated to $26 \mathrm{dpa} / 430$ appm He at $400{ }^{\circ} \mathrm{C}$. Bright-field: (a) over-focus: $+300 \mathrm{~nm}$; (b) under-focus: $-300 \mathrm{~nm}$.
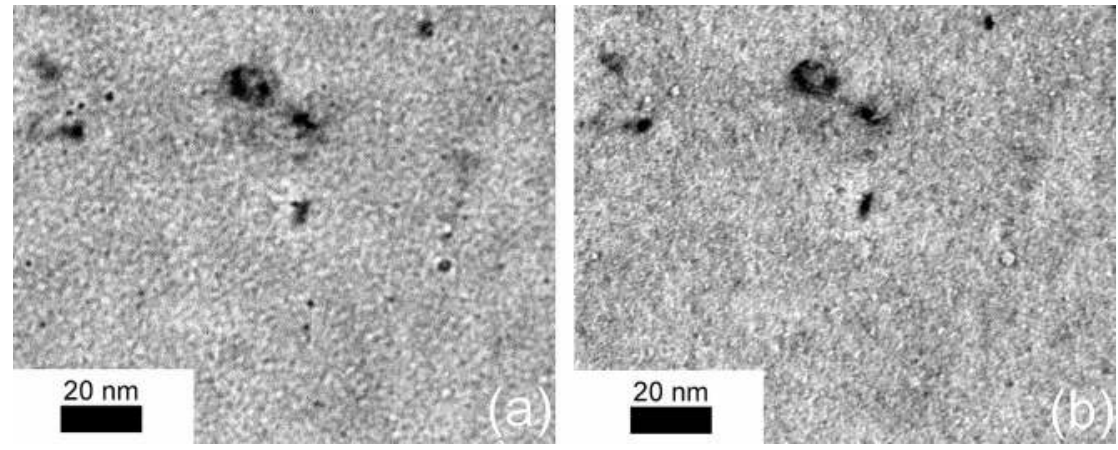

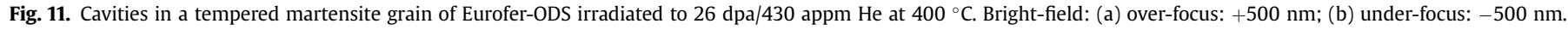
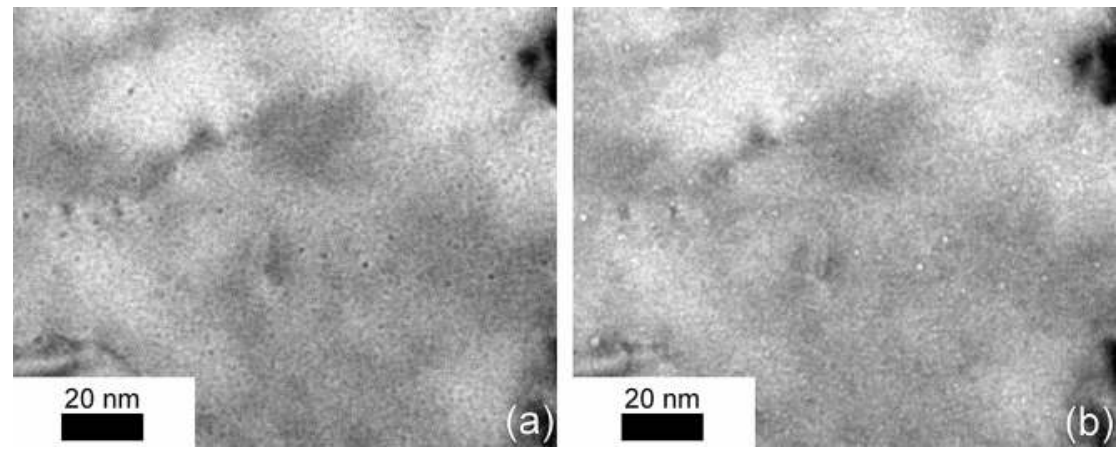

Fig. 12. Cavities in Eurofer- 97 irradiated to $27 \mathrm{dpa} / 430$ appm He/2000 appm H at $400{ }^{\circ} \mathrm{C}$. Bright-field: (a) over-focus: $+500 \mathrm{~nm}$; (b) under-focus: -500 nm.
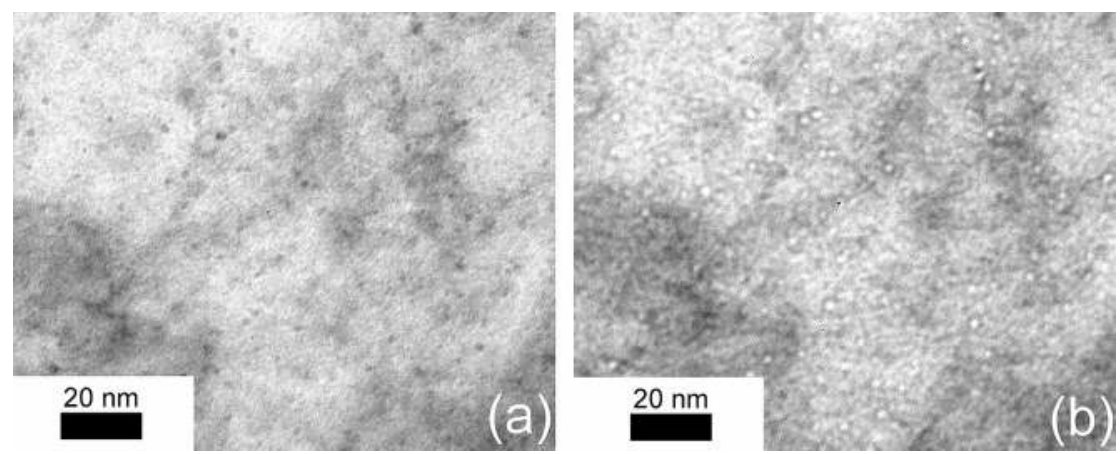

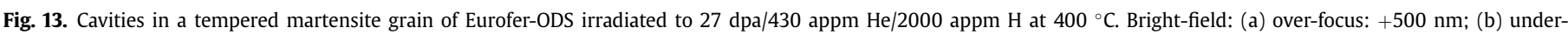
focus: $-500 \mathrm{~nm}$ 
irradiated to $100 \mathrm{dpa}$ at $400{ }^{\circ} \mathrm{C}$ and $450{ }^{\circ} \mathrm{C}$ [38]. Note that at much higher damage doses, Toloczko et al. [39] observed swelling in EP450, HT-9 and MA957 ODS to values over 1\%. Also, Getto et al. [40] observed cavities in HT9 after irradiation to 140 and 188 dpa at $440{ }^{\circ} \mathrm{C}$ with $5 \mathrm{MeV} \mathrm{Fe}^{2+}$ ions. But similar irradiations to 25 and 50 dpa did not produce any cavities [40], so their results are quite coherent with ours: F/M steels resist swelling when nucleation is not assisted by the presence of helium.

\subsection{Multi-beam irradiations of Eurofer-97 and Eurofer-ODS: effects of gas ion implantation}

After irradiation to 26 dpa and 430 appm He in dual-beam mode, we observed cavities with a density of $1.8 \times 10^{22} \mathrm{~m}^{-3}$ and a mean diameter of $1.4 \mathrm{~nm}$ in Eurofer-97. After irradiation of the same material to $16.3 \mathrm{dpa}$ and $412 \mathrm{appm}$ He in HFR [6], at conditions that one may consider similar to ours in terms of dose, temperature and helium content, the cavity microstructure was much coarser. Densities and mean cavity sizes were $0.32 \times 10^{22} \mathrm{~m}^{-3}$ and $10 \mathrm{~nm}$ at $350^{\circ} \mathrm{C}$ and $0.24 \times 10^{22} \mathrm{~m}^{-3}$ and $5 \mathrm{~nm}$ at $450^{\circ} \mathrm{C}$. As for the dislocation loops, this tends to indicate a temperature shift larger than $50{ }^{\circ} \mathrm{C}$ between ion- and neutron-irradiations, although the different helium-to-dpa ratios and the fact that all helium production is nearly finished after $1 \mathrm{dpa}$ in the HFR neutron irradiations may also alter the cavity microstructure.

As for other multi-beam irradiations of $\mathrm{F} / \mathrm{M}$ steels, they tend to confirm that ion-induced swelling remains low at $400{ }^{\circ} \mathrm{C}$. In a $\mathrm{Fe}-9 \mathrm{Cr}-1 \mathrm{Mo}$ steel, Farrell and Lee [38] observed the formation of small cavities $(\sim 2.0 \mathrm{~nm})$ after irradiation to $106 \mathrm{dpa} /$ $1040 \mathrm{appm} \mathrm{He} / 4640 \mathrm{appm} \mathrm{D}$ at $400{ }^{\circ} \mathrm{C}$, leading to a swelling of $0.08 \%$. Hiwatashi et al. [41] dual-beam irradiated $\mathrm{Fe}-9 \% \mathrm{Cr}-2 \% \mathrm{~W}$ and $\mathrm{Fe}-7 \% \mathrm{Cr}-2 \% \mathrm{~W}$ steels at $15 \mathrm{appm} \mathrm{He} / \mathrm{dpa}$ to $125 \mathrm{dpa}$ at $400{ }^{\circ} \mathrm{C}$. They observed relatively small cavities and swelling values under $0.1 \%$.

Tanaka et al. [42] irradiated $\mathrm{Fe}-12 \% \mathrm{Cr}$ and $\mathrm{Fe}-9 \% \mathrm{Cr}$ model alloys in triple-beam (Fe, He and $\mathrm{H}$ ions) and dual-beam ( $\mathrm{Fe}$ and $\mathrm{He}$ ions) modes to $50 \mathrm{dpa}$ with fusion relevant conditions. At $510{ }^{\circ} \mathrm{C}$, the comparison of these two types of irradiation demonstrated that hydrogen injection induces additional cavity growth and swelling. In our experiments, the cavity sizes and densities seem to be slightly higher when hydrogen in injected in both materials. However, due to large error bars at such small cavity sizes, it is difficult to conclude that hydrogen has effectively played a role. This discrepancy with work by Tanaka et al. may be due to the lower temperature in our study. It could also be related to the lower dose in our study: cavity growth, for which hydrogen may play a role, is not yet active. Note that Farrell and Lee concluded for their ion-irradiations of a $\mathrm{Fe}-9 \mathrm{Cr}-1 \mathrm{Mo}$ steel [38] that the coinjection of hydrogen had a low impact on the overall cavity microstructure. More dual- and triple-beam irradiations at other temperatures and doses are necessary to comprehend the effect of hydrogen.

For Eurofer-ODS, the different behaviours between the tempered martensite grains and ferrite grains under dual- and triple-beam experiments can be explained as follows. In the tempered martensite grains, implanted helium atoms will instantly be captured by a vacancy, due to the very low interstitial helium migration energy [43] and the very high quantity of vacancies created in cascades. According to our calculations done with SRIM [21] and presented in Section 2, more than fifty thousand vacancies are created for each helium atom implanted during the irradiation. The combination of a vacancy and a helium atom form a substitutional helium atom, which probably migrates via the vacancy mechanism with an activation energy close or higher than the one calculated in iron $(1.1 \mathrm{eV})$ by $a b$ initio methods [43]. Thus this substitutional helium atom may migrate over small distances at $400{ }^{\circ} \mathrm{C}$, but will also lead to the formation of small helium-vacancy clusters, nuclei of cavities. However, in the ferrite grains, it may be postulated that the higher density of nano-particles will tend to capture all helium atoms at their interfaces, reducing the possibility for nucleation of cavities in these zones. As a result, the high density of smaller ODS nano-particles in the ferrite grains inhibits cavity formation.

The question of knowing whether helium actually accumulates on ODS particles has been addressed by Badjeck et al. [44] who studied the distribution of Ti and He by EELS using an ultra-STEM in an ODS steel irradiated in dual-beam mode (Fe and He ions). In their study some of the helium was detected on ODS particles. Qian et al. [45] have also studied the distribution of helium in an ODS steel by APT after a single-beam $\mathrm{He}^{+}$irradiation at $400{ }^{\circ} \mathrm{C}$. They found that only about $5 \%$ of helium was correlated with nanoparticles. However the authors indicate that for irradiations in nuclear reactors (or dual-beam irradiations), the situation may be different due to a very different $\mathrm{He} / \mathrm{dpa}$ ratio. Experimental studies like these could help us confirm the role of the high-density of nano-particles in the ferrite grains in our case.

\section{Conclusion and acknowledgments}

We have performed single-, dual- and triple-beam ion irradiations of Eurofer-97 and Eurofer-ODS steels to $26 \mathrm{dpa}$ at $400{ }^{\circ} \mathrm{C}$. Microstructural damage was characterized by TEM. The following conclusions may be drawn for the two steels irradiated to $26 \mathrm{dpa}$ at $400{ }^{\circ} \mathrm{C}$ :

- Under single-beam $\mathrm{Fe}^{3+}$ ion irradiation, dislocation loops form in both Eurofer-97 and Eurofer-ODS. No cavities are detected.

- Simultaneous gas ion implantation does not affect the dislocation microstructure formed under irradiation. However, it induces the formation of cavities in Eurofer-97 and in the tempered martensite grains of Eurofer-ODS.

- Low cavity diameters in dual- and triple-beam modes indicate low swelling $(<0.1 \%)$ for both materials.

- A high-density of ODS nano-particles such as in the ferrite grains of Eurofer-ODS inhibits cavity formation.

Experiments done at JANNuS (Joint Accelerators for Nanoscience and Nuclear Simulation), Saclay, France and supported by EFDA (European Fusion Development Agreement) and the French network EMIR.

This work has been carried out within the framework of the EUROfusion Consortium and has received funding from the Euratom research and training programme 2014-2018 under grant agreement No 633053. The views and opinions expressed herein do not necessarily reflect those of the European Commission.

\section{References}

[1] R.L. Klueh, D.R. Harries, High-Chromium Ferritic and Martensitic Steels for Nuclear Applications, ASTM, West Conshohocken, PA, 2001.

[2] R. Lindau, et al., Fusion Eng. Des. 75-79 (2005) 989.

[3] J.L. Boutard, A. Alamo, R. Lindau, M. Rieth, CR Phys. 9 (2008) 287.

[4] M. Gilbert, S. Dudarev, S. Zheng, L. Packer, J. Sublet, Nucl. Fusion 52 (2012) 083019.

[5] J. Henry, X. Averty, A. Alamo, J. Nucl. Mater. 417 (2011) 99.

[6] M. Klimenkov, A. Möslang, E. Materna-Morris, J. Nucl. Mater. 453 (2014) 54.

[7] E. Gaganidze, J. Nucl. Mater. 417 (2011) 93.

[8] A. Möslang, CR Phys. 9 (2008) 457.

[9] L. Beck, Y. Serruys, S. Miro, P. Trocellier, E. Bordas, F. Leprêtre, D. Brimbal, T. Loussouarn, H. Martin, S. Vaubaillon, S. Pellegrino, D. Bachiller-Perea, J. Mater. Res. 30 (2015) 1183.

[10] Y. Serruys, P. Trocellier, S. Miro, E. Bordas, M.O. Ruault, O. Kaïtasov, S. Henry, O. Leseigneur, T. Bonnaillie, S. Pellegrino, S. Vaubaillon, D. Uriot, J. Nucl. Mater. 
$386-388$ (2009) 967.

[11] M. Klimenkov, E. Materna-Morris, A. Möslang, J. Nucl. Mater. 417 (2011) 124.

[12] O. Weiss, E. Gaganidze, J. Aktaa, J. Nucl. Mater. 426 (2012) 52.

[13] E. Materna-Morris, A. Möslang, R. Rolli, H.C. Schneider, J. Nucl. Mater. $386-388$ (2009) 422.

[14] R. Coppola, M. Klimenkov, R. Lindau, A. Möslang, M. Valli, A. Wiedenmann, J. Nucl. Mater. 409 (2011) 100.

[15] Z. Tong, Y. Dai, J. Nucl. Mater. 398 (2010) 43.

[16] T. Zhang, C. Vieh, K. Wang, Y. Dai, J. Nucl. Mater. 450 (2014) 48.

[17] C.A. Williams, J. Hyde, G. Smith, E. Marquis, J. Nucl. Mater. 412 (2011) 100.

[18] S.V. Rogozhkin, P. Vladimirov, A.G. Zaluzhnyi, J. Nucl. Mater. 409 (2011) 65.

[19] Rogozhkin, et al., Phys. Met. Metallogr. 113 (2012) 200.

[20] E. Gaganidze, H. Schneider, B. Dafferner, J. Aktaa, J. Nucl. Mater. 355 (2006) 83.

[21] J. Ziegler, Nucl. Instrum. Meth. B 219 (2004) 1027.

[22] R. Stoller, M. Toloczko, G. Was, A. Certain, S. Dwaraknath, F. Garner, Nucl. Instrum. Meth. B 310 (2013) 75.

[23] D. Brimbal, E. Meslin, J. Henry, B. Décamps, A. Barbu, Acta Mater. 61 (2013) 4757.

[24] D.L. Plumton, W.G. Wolfer, J. Nucl. Mater. 120 (1984) 245.

[25] F. Garner, J. Nucl. Mater. 117 (1983) 177.

[26] R. Schaüblin, D. Gelles, M. Victoria, J. Nucl. Mater. 307-311 (2002) 197.

[27] Z. Yao, M. Hernandez-Mayoral, M.L. Jenkins, M. Kirk, Phil Mag. 88 (2008) 2851.

[28] S. Xu, Z. Yao, M. Jenkins, J. Nucl. Mater. 386 (2009) 161.

[29] A. Prokhodtseva, B. Décamps, A. Ramar, R. Schäublin, Acta Mat. 61 (2013) 6958.

[30] M. Jenkins, M. Kirk, Characterization of Radiation Damage by Transmission Electron Microscopy, IOP Publishing, 2001.
[31] D.B. Williams, C.B. Carter, Transmission Electron Microscopy, second ed. Springer, 2009.

[32] R. Lindau, A. Möslang, M. Schirra, P. Schlossmacher, M. Klimenkov, J. Nucl. Mater. 307-311 (2002) 769.

[33] J. Hoffmann, Personal Communication.

[34] L.L. Horton, J. Bentley, K. Farrell, J. Nucl. Mater. 108\&109 (1982) 222.

35] D.S. Gelles, J. Nucl. Mater. 108\&109 (1982) 515.

[36] S.L. Dudarev, R. Bullough, P.M. Derlet, Phys. Rev. Lett. 100 (2008) 135503.

[37] J. He, F. Wan, K. Sridharan, T.R. Allen, A. Certain, Y.Q. Wu, J. Nucl. Mater. 452 (2014) 87.

[38] K. Farrell, E.H. Lee, Effects of radiation on materials, in: F. Garner, J. Perrin (Eds.), 12th Int Symp, ASTM STP 870, ASTM, 1985, p. 383

[39] M.B. Toloczko, F.A. Garner, V.N. Voyevodin, V.V. Bryk, O.V. Borodin, V.V. Mel'nychenko, A.S. Kalchenko, J. Nucl. Mater. 453 (2014) 323.

[40] E. Getto, Z. Jiao, A.M. Monterrosa, K. Sun, G.S. Was, J. Nucl. Mater. 462 (2015) 458-469, http://dx.doi.org/10.1016/j.jnucmat.2015.01.045.

[41] S. Hiwatashi, Y. Kohno, K. Asakura, A. Kohyama, J. Nucl. Mater. 179-181 (1991) 709 .

[42] T. Tanaka, K. Oka, S. Ohnuki, S. Yamashita, T. Suda, S. Watanabe, E. Wakai, J. Nucl. Mater. 329-333 (2004) 294.

[43] C.C. Fu, F. Willaime, Phys. Rev. B 72 (2005) 064117.

[44] V. Badjeck, M. Walls, E. Meslin, A. Bhattacharya, L. Chaffron, in: Electron Microscopy and Spectroscopy for the Study of Helium Cavities and Radiation Damage in Oxide-Dispersion Strengthened Steels, presented at the NuMat Conference, 2014.

[45] L. Qian, C.M. Parish, K.A. Powers, M.K. Miller, J. Nucl. Mater. 445 (2014) 165 